\title{
OBSERVATION ON THE ULTRA STRUCTURE OF MAST CELLS IN INGUINAL CRYPTORCHID TESTES OF THIRTEEN-YEAR-OLD CHILDREN
}

\author{
Ali Abalkhail", Ibrahim Bani Hani", Fakhri Al-Bagdadi** and Younis Abu-Ghalyun ${ }^{* * *}$ \\ *Jordan University of Science and Technology Faculty of Medicine, Department of Urogenital \\ Surgery and Department of Pathology, Irbid, Jordan, ${ }^{* *}$ Louisiana State University, Skip Bertman \\ Drive, Department of Comparative Biomedical Sciences, Baton Rouge, LA, USA ${ }^{* * *}$ Yarmouk \\ University, Department of Biology, Irbid, Jordan.
}

Ten per cent of the testicular tumors in humans were associated with cryptorchidism (1). The degenerative morphological changes of inguinal testis has been examined in equine (2), and the pathology of the ultra structure of inguinal testes has been briefly reported in human (3). Mast cells were increased in testis affected by hydropathic pathology (4). Mast cells are not present in human testis (5). We report here observations on the mast cells and ultrastructural pathomorphology of inguinal cryptorchid testes of children thirteen years old. Ultrastructural morphological documentation of inguinal cryptorchid testes in correspondence to the age of the child is inconsistent and lacking. The presence of mast cell and its role in cryptorchidism needs definition.

Three children, ages thirteen years, were diagnose with unilateral inguinal cryptorchid testis were surgically corrected at Princess Basmah Teaching Hospital of Jordan. Biopsies were minced and fixed in cold $2 \%$ glutaraldehyde and a sodium Cacodylate buffer of $\mathrm{pH} 7.4$; washed in the same buffer and post fixed in 1\% osmium tetroxide for sixty minutes and routinely processed for electron microscopy. Silver sections were cut and stained with uranyl acetate and lead citrate. The sections were examined by Zeiss-10 electron microscope and photographed by black and white Kodak plate film in Yarmouk University, Irbid, Jordan.

The inguinal testes of the examined children were harder and smaller than the normal contralateral gonad.Vacuoles were present in the peritubular connective tissue of the fibroblasts (Figures 1,2) and in mast cells (Figure 1). The nuclei of these mast cells were elongated with irregularly marginated, patched heterochromatin. The nuclei of the fibroblasts contained mainly heterochromatin (Figures 1,2). Several elongated mast cells contained secretory granules at different stages of maturation (Figure 1). These mast cells were scattered between the peritubular connective tissue, in the vicinity of the seminiferous tubules (Figure 1). Bundles of collagen fibers, at various types of orientation, very closely bordered the plasmalemma of the mast cells and the basement membrane of the seminiferous tubules (Figures 1,2). Some of the examined biopsies showed several dilated blood vessels at the vicinity of the peritubular connective tissue. These blood vessels were engorged with red blood corpuscles (Figure 2).

Mast cells are consistant cell type of human testis from birth to childhood (6). It has been reported that mast cells are not present in the human testes (7). Several mast cells appeared in the peritubular connective tissue in the vicinity of the seminiferous tubules of the examined biopsies. Degranulation of some of the mast cells indicates their activity, which has been reported to take place only in pathological conditions (7). An increase in the number of mast cells was reported in the testes of patients with idiopathic male infertility (4). Mast cells have been reported to increase in 
number as a response to premalignant or neoplastic proliferation. The presence of mast cells in this study raises the question on their role in cryptorchidism. Mast cells increase in allergic and inflammatory conditions (6) and they are involved in testes infertility (8). Dilated blood vessels associated with the seminiferous tubules. The dilation of the blood vessels and the presence of mast cells are an indication of inflammatory reaction. This might indicate that inguinal testis is inflamed and is undergoing pathological changes timewise.

\section{References}

[1] H. Brendler, Progr. in Clin. and Biol. Res. (1985). New York, Alan R, Liss, 189-196.

[2] F. Al-Bagdadi et al., Int.J.Fertil. 36 (1991) 57-64.

[3] I. Bani Hani et al., Proc 52 ${ }^{\text {nd }}$ Annu. Meet. Electron Microscopy Soc. Am. (1994) 88-89.

[4] A. Montella et al., Bolletino-Societa-Italiana-Biologica-Sperimentale. 68, 2 (1992) 77-84

[5] S. Majeed., Arzneimittelforschung. 44, 10 (1994) 1170-3

[6] M. Nistal et al., Acta. Anat., 119 (1984) 155-160.

[7] Y. Maseki et al., Fert. Steril. 36 (1981) 814-817.

[8] V. Meineke et al., Fert. Steril. 74,2 (2000) 239-44

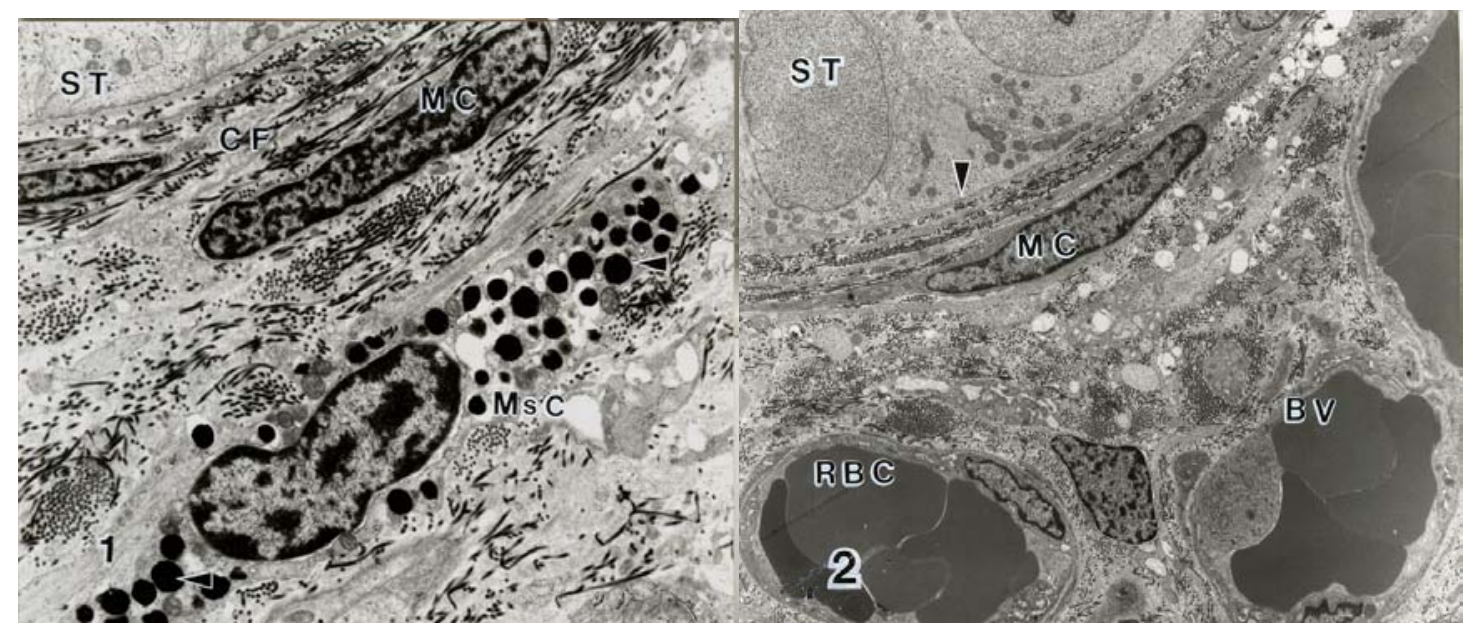

Figure 1. A thirteen-year-old child with inguinal cryptorchid testis shows seminiferous tubule ( ST) bordered by peritubular collagenous connective tissue. An elongated mast cell (MsC) contains cytoplasmic secretory granules (arrows) separated from the seminiferous tubule by bundles of collagen fibers (CF) and myoid cells (MC). Stained with uranyl acetate and lead citrate X 6200 . Figure 2. A thirteen-year-old child with inguinal cryptorchid testis shows seminiferous tubule (ST). The peritubular connective tissue is mainly collagen fibers and a myoid peritubular cell (MC). Dilated blood vessels (BV) filled with red blood cells RBC. Stained with uranyl acetate and lead citrate X 265 